\title{
Fine-scale recognition and use of mesoscale fronts by foraging Cape gannets in the Benguela upwelling region
}

\author{
Sabarros Philippe S. ${ }^{1,2, *}$, Gremillet David ${ }^{3,4}$, Demarcq Herve ${ }^{2}$, Moseley Christina ${ }^{4}$, Pichegru Lorien ${ }^{4}$, \\ Mullers Ralf H. E. ${ }^{3}$, Stenseth Nils C. ${ }^{1,5}$, Machu Eric ${ }^{1,6,7}$
}

${ }^{1}$ Univ Oslo, Dept Biol, Ctr Ecol \& Evolutionary Synth, N-0316 Oslo, Norway.

2 Inst Rech Dev, Ctr Rech Halieut Mediterraneenne \& Trop, UMR EME 212, F-34203 Sete, France.

${ }^{3}$ CNRS, Ctr Ecol Fonct \& Evolut, F-34293 Montpellier, France.

${ }^{4}$ Univ Cape Town, DST NRF Ctr Excellence, Percy Fitzpatrick Inst African Ornithol, ZA-7701

Rondebosch, South Africa.

${ }^{5}$ Inst Marine Res, Flodevigen Marine Res Stn, N-4817 His, Norway.

${ }^{6}$ Inst Rech Dev, Lab Phys Oceans, F-29280 Plouzane, France.

${ }^{7}$ Ifremer, France

* Corresponding author: Philippe S. Sabarros, Tel.: +47 22854 400; fax: +47 22854001 ;

email address : p.s.sabarros@bio.uio.no

\begin{abstract}
:
Oceanic structures such as mesoscale fronts may become hotspots of biological activity through concentration and enrichment processes. These fronts generally attract fish and may therefore be targeted by marine top-predators. In the southern Benguela upwelling system, such fronts might be used as environmental cues by foraging seabirds. In this study we analyzed high-frequency foraging tracks (GPS, 1 s sampling) of Cape gannets Morus capensis from two colonies located on the west and east coast of South Africa in relation to mesoscale fronts detected on daily high-resolution chlorophyll-a maps (MODIS, $1 \mathrm{~km}$ ). We tested the association of (i) searching behavior and (ii) diving activity of foraging birds with mesoscale fronts. We found that Cape gannets shift from transiting to area-restricted search mode (ARS) at a distance from fronts ranging between 2 and $11 \mathrm{~km}$ (median is $6.7 \mathrm{~km}$ ). This suggests that Cape gannets may be able to sense fronts (smell or vision) or other predators, and that such detection triggers an intensified investigation of their surroundings (i.e. ARS). Also we found that diving probability increases near fronts in 11 out of 20 tracks investigated (55\%), suggesting that Cape gannets substantially use fronts for feeding; in the remaining cases (45\%), birds may have used other cues for feeding including fishing vessels, particularly for gannets breeding on the west coast. We demonstrated in this study that oceanographic structures such as mesoscale fronts are important environmental cues used by a foraging seabird within the rich waters of an upwelling system. There is now need for further investigations on how Cape gannets actually detect these fronts.
\end{abstract}

Keywords : Seabird, Environmental cue, Behavioral shift, Area-restricted search, Feeding activity, Fractal landscape, Oceanographic fronts, Morus capensis, Southern Benguela, South Africa 


\section{INTRODUCTION}

$$
\text { Oceanic circulation and light availability play a key role in structuring }
$$
ecosystems throughout the oceans. Oceanic circulation is crucial to supplying nutrients to the layer that light penetrates, and thereby sustaining and shaping primary productivity of marine food webs. Depending on the size, life span and diet of marine species, primary production may constrain the distribution of marine species across various spatiotemporal scales (Longhurst 1998). Hydrodynamic features - from larger scales (100s km) to smaller scales (e.g. mesoscale, 1-2 km to 100-200 km) - are known to drive the distribution and foraging patterns of top-predators because the predictability of prey is higher in and around these structures (Weimerkirch 2007). It has been well documented that large convergence zones (e.g. polar front) correspond to foraging areas of marine birds and mammals (review by Bost et al. 2009). At smaller scales, dynamic mesoscale structures such as eddies, vertically-structured fronts and filaments are essential to the enrichment, concentration and retention of nutrients and planktonic organisms in surface waters (Bakun's triad, cf Bakun 1996) which attract and shape the aggregation patterns of plankton-eaters such as small pelagic fish (Bakun 2006, Bertrand et al. 2008, Sabarros et al. 2009). Mesoscale structures are considered as major attracting features for large predatory fish (Young et al. 2001, Seki et al. 2002), marine mammals (Campagna et al. 2006, Cotté et al. 2007) and seabirds (Nel et al. 2001, Weimerskirch et al. 2004, 2005, Ainley et al. 2005, 2009, Hyrenbach et al. 2006).

How top-predators find these structures - notably fronts - still remains poorly understood. Nevitt $(2000,2008)$ showed that a range of seabirds (procellariiforms) track and capitalize on fronts across different scales using olfactory and visual cues. Procellariiforms navigate at large scales by following odor compounds (e.g. dimethyl sulfide) that are released by plankton organisms that accumulate at fronts. Once in the visual range of fronts, procellariiforms may locate and dive onto fish patches. Only a limited number of studies investigated the association between particular foraging behavioral patterns in animal movements and environmental features. For example, Trathan et al. (2008) showed that king penguins at South Georgia concentrate their foraging effort to water masses with a particular temperature range, and Tew-Kai et al. (2009) demonstrated that frigate birds feed at the edge of mesoscale eddies in the Mozambique channel. There is a crucial need for such insight to improve our 
understanding of the underlying mechanisms of seabird foraging behavior (Tremblay et al. 2009).

Eastern boundary upwelling systems (EBUS) are subtropical coastal oceanic regions where an important atmospheric forcing (i.e. winds) induces an offshore transport of surface waters that are replaced by nutrient-rich waters from subsurface layers (Capet et al. 2008). This newly upwelled water supports intense primary and secondary production that sustains the world's highest fish biomass and fisheries (Pauly \& Christensen 1995, FAO 2001). In EBUS, mesoscale features such as eddies, vertically-structured fronts, and filaments, are generated by the instability of alongshore currents superimposed on the offshore Ekman transport of surface waters (Capet et al. 2008) especially close to the shore (Pedlovsky 1978, Durski \& Allen 2005). Local enrichment and concentration of nutrient in mesoscale features promotes plankton production (Bakun 2006) and may thereby attract schools and clusters of planktivorous fish (e.g. Ainley et al. 2005, Sabarros et al. 2009). Surface mesoscale fronts associated to eddies, filaments and vertically-structured fronts are common in the southern Benguela upwelling - one of the major EBUS - located off the coast of South Africa and may well attract the most abundant planktivorous fish in that region such as the sardine Sardinops sagax and the anchovy Engraulis encrasicolus (van der Lingen et al. 2006).These pelagic fish constitute the main prey items of a mediumranging seabird: the Cape gannet Morus capensis that breeds at two colonies located on the western and the eastern coasts of South Africa (Hockey et al. 2005). Cape gannets forage within the productive waters of the Benguela upwelling system on the continental shelf (Pichegru et al. 2007) and might therefore use fronts as environmental cues when foraging. Foraging mechanisms and cues used by Cape gannets are poorly known apart from the fact that Cape gannets sometimes scavenge fishing boat discards on the west coast of South Africa (Grémillet et al. 2008).

The influence of mesoscale oceanic structures of only a few kilometers on the distribution and foraging patterns of top predators has been little investigated due to the difficulty of observing properly these patterns by satellites (e.g. Tew-Kai et al. 2009) or field measurements (e.g. van Franeker et al. 2002). Thanks to technological advances in both satellite remote sensing (e.g. high-resolution chlorophyll- $a$ measurements) and seabird biotelemetry (e.g. high-frequency GPS) we are now able to study foraging patterns of marine predators in relation to their environment at the lower mesoscale (few kms). In the present study we use for the first time a 
123 combination of high-precision individual GPS tracks (1 s sampling) of Cape gannets

124 and high-resolution daily maps of chlorophyll-a $(1 \mathrm{~km})$ provided by MODIS on which

125 we have identified mesoscale fronts (with edge detection algorithm). We assume here

126 that chlorophyll- $a$ fronts are a proxy for the occurrence of seabirds' prey as shown in

127 various studies (e.g. Ainley et al. 2005, Bakun 2006, Sabarros et al. 2009). From GPS

128 tracks we have extracted the bird's searching behavior (i.e. area-restricted search

129 ARS) and feeding activity (i.e. dives). We use our datasets to test associations of (i)

130 searching behavior and (ii) diving activity with the presence and location of

131 mesoscale fronts in the Benguela upwelling system. We expect that the proximity of

132 fronts will induce intensified search patterns by Cape gannets and that feeding activity

133 will be concentrated around fronts.

MATERIAL AND METHODS

137

138

Seabird tracks.

Foraging movements of breeding Cape gannets were monitored at two South

140 African colonies during the reproductive season of 2009 (October-November). Adults

141 raising 2-6 week-old chicks were fitted with miniaturized high-precision GPS data-

142 loggers (TechnoSmart, Rome, Italy) that were sealed in heat-shrinkable tubing (120 x

14355 x $30 \mathrm{~mm} ; 45 \mathrm{~g}$ including waterproof housing). The unit weighted approximately

$1441.8 \%$ of the body mass of an adult gannet, which was below the $3 \%$ limit

145 recommended for deploying loggers on flying birds (Phillips et al. 2003). Loggers

146 were attached to the base of the tail (below the preen gland) on three central tail

147 feathers with waterproof Tesa tape. This attachment method did little damage to the

148 plumage and the tape could be removed entirely upon recapture (Wilson et al. 1997).

149 Handling lasted 4 to $10 \mathrm{~min}$ from capture to release. Nests were then monitored

150 regularly from 6h00 to 19 h00 (South African standard time) until the bird returned.

151 The loggers recorded the position of the bird with an accuracy of 1-3 m, its speed, and

152 additional precision parameters (e.g. number of satellite signals received, dilution of

153 precision: DOP) every second. We selected the tracks that could be associated to

154 chlorophyll- $a$ maps of decent quality (see “Chlorophyll- $a$ data” part). We used a total

155 of 20 individual GPS tracks (no pseudo-replication) of which 9 were recorded on the

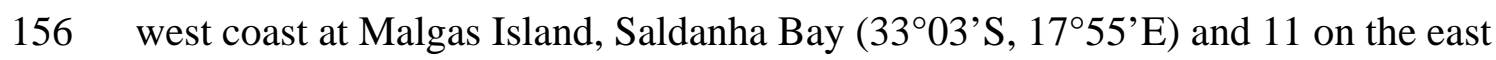




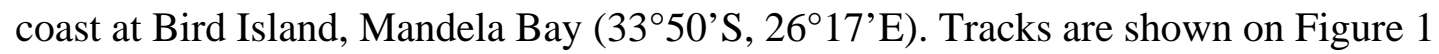
and a summary of the track characteristics is provided in Table 1.

\section{Seabird foraging activity.}

Area-restricted search (ARS). ARS describes an intense search activity performed by a foraging animal that can be useful to study foraging activity and preferential feeding grounds (Fauchald 2009, Tremblay et al. 2009). ARS behavior can be inferred from animal movement data using the fractal landscape (FL) method (Tremblay et al. 2007). FL is based on the computation of a fractal measure: the fractal dimension $D$. $D$ measures the complexity and heterogeneity of a spatial or temporal object and considers both time and space coverage. The principle of FL is to compute $D$ along the track inside a sliding time window as defined by Tremblay et al. (2007); here the time window was approximately $1 \mathrm{~h}$ (Sabarros et al. in prep). The computation of $D$ was performed using the divider method, following Nams (1996). Straight pathways are characterized by a $D$ that is close to $1 . D$ increases with track convolutions and can readily detect intense foraging patterns characterized by frequent turns and resultant tortuosity. In FL, the peaks of $D$ found along the path represent the ARS behavior (Tremblay et al. 2007, Sabarros et al. in prep).

Feeding activity. Cape gannets generally plunge dive from the air to catch prey underwater, but occasionally perform surface-dives when sitting at the sea surface (Ropert-Coudert et al. 2004). Dive durations generally average 2-5 s but dives $>5 \mathrm{~s}$ may occur (Ropert-Coudert et al. 2004, Pichegru et al. 2007). When a GPS receiver is submerged it stops collecting information sent by the satellite(s) since the signal is lost. We used high-frequency tracks ( $1 \mathrm{~s}$ ) to infer the location and duration of dives from the interruptions in GPS signal. Dives were defined as interruptions $>1$ s and $<$ $30 \mathrm{~s}$. Interruptions $>30 \mathrm{~s}$ are likely due to satellite signal reception problems or receiver malfunctioning since Cape gannet maximum dive duration is $22 \mathrm{~s}$ (RopertCoudert et al. 2004). Dive locations were assigned to the location fix preceding the interruption of the signal. We rechecked every dive profiles (including speed and signal reception) and found out that $95 \%$ of the interruptions in the signal $>1$ s and $<$ 30 s corresponded to either plunge dives (see details in Supplementary Material S1) or surface dives.

\section{Chlorophyll-a data.}


High-resolution satellite swaths (level 1 product, $1 \mathrm{~km}$ spatial resolution) of chlorophyll- $a$ from Moderate Resolution Imaging Spectroradiometer (MODIS) satellite missions (Aqua and Terra) run by NASA (oceancolor.gsfc.nasa.gov) were used to compile gridded daily maps at $1 \mathrm{~km}$ spatial resolution. Wavelengths of the visible spectrum are used to monitored chlorophyll- $a$. Visible wavelengths are sensitive to clouds, hence cloudy days lead to maps with poor data coverage. For the purpose of our study, only cloud-free chlorophyll- $a$ maps could be associated to bird tracks.

\section{Mesoscale chlorophyll- $a$ fronts.}

Fronts in upwelling areas were detected using an extension of the single-image edge detection (SIED) algorithm of Canyula \& Cornillon (1992) as described in Nieto (2009). The basic idea of SIED method is to use overlapping windows to investigate the statistical likelihood of an edge by detecting bimodality in histogram distribution and checking for cohesiveness of the potential edge (Canyula \& Cornillon 1992).

Nieto's method (2009) significantly improves the number and the length of boundaries detected between water masses (compared to the original method) and allows the detection of continuous fronts. The computation of SIED on high-resolution chlorophyll- $a$ maps allows the identification of surface oceanic features such as mesoscale fronts. Fronts appear as curves and lines (see chlorophyll- $a$ map with fronts in Fig. 2).

\section{Fronts vs. seabird foraging behavior}

We chose to investigate the potential influence of fronts on Cape gannet searching behavior and feeding activity by examining the proximity of foraging birds to fronts. For each positional fix along the bird's pathway we calculated the distance of the bird to all fronts and selected among them the distance of the bird to the nearest front $(d)$. Daily chlorophyll- $a$ maps (with the position of fronts) were assigned to tracks according to the date (generally spanning over one day, sometimes two days) with a maximum lag of \pm 1 day difference between the chlorophyll- $a$ map and the time of each positional fix considered (see Tab. 1). Fronts are dynamic structures and the distance fronts can travel in $24 \mathrm{~h}$ may vary. Consecutive cloud-free maps of chlorophyll- $a$ were rarely available and we could not therefore evaluate front displacement with precision. Fronts were however assumed to be relatively stable on 
225 the short-term (e.g. $24 \mathrm{~h}$ ) and their displacement to be negligible compared to the distances covered by birds.

First, we investigated the influence of fronts distance on birds searching behavior.

228 Searching intensity was characterized by the fractal dimension $D$ in the FL method

229 (Tremblay et al. 2007). For each track we generated figures with $D$ calculated for each

230 positional fix on the $\mathrm{Y}$-axis, and the corresponding distance to the nearest front $d$ on

231 the X-axis (see Fig. 3, Supplementary Material S3). We designed an automated

232 algorithm to detect a potential behavioral shift on $D$ relative to the distance $d$ to the

233 nearest front: we systematically tested a range of 100 thresholds defined within the

234 range of $d$ found in each track. Each threshold $\left(d_{\text {shift }}\right)$ delimited two data subsets: the

235 first group corresponds to observations of $D$ when $d \leq d_{\text {shift, }}$ and the second group

236 when $d>d_{\text {shift }}$. We tested the difference in mean and variance between the two subsets

237 by using Student's $t$-tests and the F-tests (ANOVA) respectively. Because consecutive

238 calculations for $D$ along the track are not independent from each other and because F-

239 test requires balanced data, we performed 1000 bootstraps of the method described

240 above by resampling in each empirical distribution a subset of size $\mathrm{N}$ that corresponds

241 to the smaller of the two subsets (Manly 2007). The position of the shift was chosen

242 as the distance threshold $\left(d_{\text {shift }}\right)$ for which the difference in mean between the subsets

243 was the largest, and that verified that the respective means and variances were

244 significantly different (see example of this procedure in Supplementary Material S2).

245 Secondly, we tested the effect of the distance to the nearest front on diving

246 activity. We used a generalized linear model for binomial response (binomial

247 regression; logit link function) to explain the occurrence of diving events (Dive:

248 categorical response variable, Dive $=1$ if dive occurs, Dive $=0$ if not) relative to front

249 distance ( $d$ : explanatory variable). The probability to realize Dive $=1$ was modeled as

250 a function of front distance: $\operatorname{Pr}(z)=1 / 1+\exp (-z)$, where the probability to dive $(\operatorname{Pr})$ is

251 a function of front distance ( $d$ in $\mathrm{km}$ ) with $\mathrm{z}$ as the linear predictor $\mathrm{z}=\alpha+\beta \oplus d, \alpha$ as

252 the intercept and $\beta$ as the regression parameter on $d$. Because the number of

253 observations associated with dives $\left(\mathrm{N}_{1}\right)$ was often 100 times more than the number of

254 observations without dives $\left(\mathrm{N}_{0}\right)$ we used a bootstrap procedure to accommodate for

255 unbalanced observations of categorical data (Davison \& Hinkley 1997, Manly 2007).

256 One bootstrap iteration consisted in resampling $\mathrm{N}_{1}$ observations from the empirical

257 distribution of the non-associated-to-dives observations, and running the model 
described above. Observations associated with dives were independent from each other while observations non-associated with dives were originally correlated to each

260 other. By resampling $\mathrm{N}_{1}$ from $\mathrm{N}_{0}$ observations of Dive $=0$ while $\mathrm{N}_{0}>>\mathrm{N}_{1}$, the 261 consecutive and dependent observations of Dive $=0$ have less chance of appearing in 262 the same bootstrap subset, hence resolving the issue of non-independent data. We 263 performed 1000 bootstraps to obtain bootstrapped distributions for $a, b$, and the 264 associated $p$ values. The probability and its bootstrapped 95\% confidence interval 265 (drawn from 1000 simulations of $\operatorname{Pr}($ Dive $=1 \mid d$ ) with $\alpha$ and $\beta$ in their respective 266 bootstrap distribution) were plotted as a function of $d$ to illustrate the effect of the 267 latter on diving activity (see Fig. 5, see more in Supplementary Material S4).

\section{RESULTS}

ARS behavior.

The shift identification procedure (described and illustrated in Supplementary 274 Material S2) successfully identified in each track a threshold distance to the nearest 275 front $\left(d_{\text {shift }}\right)$ that delimits two behavioral modes. Figure 3 illustrates this in track M2: $276 d_{\text {shift }}$ delimits a mode where $D$ is higher and of greater variance near fronts $\left(d \leq d_{\text {shift }}\right)$ 277 from a mode with a lesser $D$ (close to 1 ) and with a reduced variance for locations that 278 are away from fronts $\left(d>d_{\text {shift }}\right)$. This pattern was found in all investigated tracks (see 279 Supplementary Material S3), except tracks M7 and M8 that remained untested 280 because the computation of the FL method failed (technical issue we did not get a 281 chance to fix). Differences in mean and variance are significant (respectively $t$-test 282 and F-test with $p<0.001$, Tab. 2). The threshold distance to the nearest front $d_{\text {shift }}$ 283 ranges from 1.3 to $22 \mathrm{~km}$ with $6.7 \mathrm{~km}$ as the median (Fig. 4, Supplementary Material 284 S3).

Feeding activity.

Figure 2 shows a foraging trip performed by a Cape gannet from Malgas Island 288 (track M1). Dives located in the outermost part of the track occurred in the vicinity of 289 a front. The binomial regression parameter $\beta$ (estimated by the bootstrap procedure) 290 that characterizes the effect of the distance to the nearest front $d$ on diving is 291 presented in Table 2 . The estimation for $\beta$ significantly differs from 0 in 11 out of 20 
tracks (55\%, Tab. 2). This suggests that diving activity is significantly linked to the distance of fronts in slightly more than half of the cases. This is illustrated in Figure 5

294 (example of track B1) by the negative relationship between the probability of diving $295 \operatorname{Pr}($ Dive $=1)$ and the distance to the nearest front $d$. Diving probability increases with 296 the proximity of fronts (Fig. 5 for track B1, see Supplementary Material S4 for the 297 other tracks). The probability that a dive occurs at the exact position of a front (i.e. at $298 d=0$ ) ranges from 0.56 to 0.87 , with a median value of 0.69 (Tab. 3, Fig. 6). For cases where the diving activity is not linked to fronts (45\% of the tracks) this probability ranges from 0.37 to 0.62 (median is 0.44 , Tab. 2) and only varies marginally with the distance of fronts (see Supplementary Material S4). When comparing regions, we find that diving activity is significantly linked to fronts in $44 \%$ of the tracks (4 out of 9 at Malgas Island) monitored on the west coast in contrast to $64 \%$ (7 out of 11 at Bird Island) on the east coast (Tab. 2).

\section{DISCUSSION}

Our study presents evidence that within the rich waters of the continental shelf of the west and east coasts of the southern Benguela system Cape gannets track and use oceanic structures such as mesoscale fronts. Here we provide new insights into the mechanisms that link foraging patterns, i.e., searching (ARS) and feeding activity, to the presence and location of mesoscale fronts. Searching behavior of Cape gannets

314 changes from transiting to ARS with the proximity of fronts and more than half the birds feed substantially more near fronts.

\section{Detection of front triggers ARS}

Cape gannets exhibit a distinct behavioral shift when approaching fronts at a median distance of $6.7 \mathrm{~km}$. This behavioral shift delimits two modes: supposedly active prey searching i.e. ARS ( $D>1$ with high variance), and transiting ( $D \approx 1$ with reduced variance). Near fronts, ARS mode is characterized by a higher $D$ that indicates that the pathway is convoluted and hence that the bird is actively investigating the surroundings by making frequent turns. This ARS mode is also

324 characterized by a more variable $D$ (i.e. high $D$ but also low $D$ parts) that suggests that 325 ARS is here a combination of convoluted and straight bouts. The transiting mode that 
occurs away from fronts and that is characterized by straight movements likely corresponds to commuting between colonies and feeding grounds for instance.

Perception of environmental cues is crucial to seabirds for acquiring reliable information on their environment (Fauchald 2009). Fronts concentrate and enhance biological activity and thus the predictability of finding prey is generally enhanced at fronts regardless of the scale considered (Weimerskirch 2007, Bost et al. 2009). A mesoscale chlorophyll- $a$ front may correspond to the subduction between two water masses that differ in chlorophyll- $a$ concentration and hence in color (blue for low chlorophyll- $a$ concentrations and greenish for higher concentrations). Occasionally there can be a local surface enhancement along the front (Capet et al. 2008). These oceanographic structures can be detected by satellites (remote sensing, e.g. MODIS) and probably by seabirds that fly over the oceans too. Here Cape gannets use mesoscale fronts as environmental cues in the Benguela upwelling system. Tracking these fronts and initiating ARS when detecting such structures may enable a mediumranging such as the Cape gannet to maximize prey encounters (see also Ainley et al. 2005).

Perception range is a critical aspect of sensory ecology since it is linked to foraging success (Barraquand et al. 2009). Birds detecting fronts by sight would be expected to initiate ARS at a relatively constant distance (liable to individual variability) that would correspond to their visual range. This is clearly not the case in our study since Cape gannets switch to ARS at distances ranging from 1.3 to $22 \mathrm{~km}$. Phytoplankton concentrated by fronts produces dimethyl sulfide (DMS) when grazed by zooplankton. DMS can be sensed by a range of seabirds (procellariiforms) that use this odor compound as a navigation cue (Nevitt 2000). Procellariiforms, for example, use DMS to locate potential feeding zones at large scales, such as upwellings, sea mounts and shelf breaks (Nevitt 2000, 2008). We argue that Cape gannets might also be able to smell DMS emitted by phytoplankton, and hence use the odor landscape to navigate towards favorable feeding areas and eventually trigger ARS. Depending on wind speed and direction, DMS molecules may reach gannets at varying distances from the location where they were emitted. This may explain why the distance of the shift from transiting to ARS behavior varies by a factor of 17. Other predators' behavior (e.g. congeners, other seabirds, subsurface predators) may inform a foraging Cape gannet on the local environment and for example give indication on where to concentrate its attention. Encountering by chance predators that seem to be heavily 
searching for prey may drive a Cape gannet to initiate ARS. The predators used as cues by Cape gannets may be located more or less close to a front or may not even be associated to any front. This provides a possible explanation for the great variance that characterizes the distance to fronts at which Cape gannets shift from transiting to ARS. Finally, fronts are highly dynamic features and because the time lag between the chlorophyll- $a$ snapshots (daily maps) and the bird's positions reached $24 \mathrm{~h}$ in some cases, this could be a source of error that would also explain the observed variability in the behavioral shift distance.

\section{Fronts: selected feeding grounds}

Diving activity and by extension feeding activity of Cape gannets increases near fronts in a substantial number of the GPS tracks investigated in this study (55\%). Fronts appear to be preferred feeding locations on these tracks, as the probability of diving at fronts averages 0.7 (and is always higher than 0.56). As partly argued above, Cape gannets may use a combination of olfactory and visual cues at smaller scales to locate prey patches in the vicinity of fronts (comparably to procellariiforms, Nevitt 2000, 2008). The main prey of Cape gannets (sardine and anchovy) are planktivorous fish (van der Lingen et al. 2006) and are therefore likely to be found in large aggregations at/near fronts (e.g. Ainley et al. 2005, Bakun 2006, Sabarros et al. 2009). Moreover, spotting prey in frontal zones may be facilitated by the presence of subsurface predators (i.e. large predatory fish, pinnipeds, cetaceans or other seabirds) that force fish schools towards the surface (Evans 1982, Le Corre \& Jacquemet 2005). At small scales again, fronts may be useful oceanic structures to capitalize on, because once tracked by smell or other means, they allow prey detection by sight from a closer distance.

\section{Use of other cues}

Diving activity was not increased near fronts compared to other locations in $45 \%$ of the birds ( $N=9 / 20)$ even though these birds exhibited a shift in searching behavior that was related to fronts on larger scales. The probability of diving near fronts ranged around 0.5 (0.37-0.62), indicating that diving was not linked to fronts. These birds may have initiated ARS when detecting fronts but they probably used other cues for feeding. There are a few possible explanations to that. Feeding activity may not be associated with fronts in that case because these birds may have encountered patches 
of prey in locations that are away from fronts while transiting for example (Weimerskirch 2007, Sabarros et al. in prep). These Cape gannets may also have found patches thanks to successful foraging congeners or other species (e.g. other seabirds species, subsurface predators). Finally this may suggest that birds have interacted with trawler boats like northern gannets in the UK (Votier et al. 2009). Bottom trawlers in the southern Benguela generally fish along the continental break shelf regardless of surface mesoscale fronts (see Fig. 1 in Grémillet et al. 2008). Vessel monitoring systems (VMS) data from fishing boats would have been here useful to test if Cape gannets do follow and interact with fishing boats (bottom trawlers and purse-seiners).

The stocks of the preferred prey of Cape gannets (sardines and anchovies) previously associated with the Western Cape province have shifted eastward in late 1990s towards the Eastern Cape province (Crawford et al. 2008). Following the shortage of prey on the west coast, the population of Cape gannets in this region decreased (Crawford et al. 2008). The eastward shift of prey has resulted in Cape gannets of Malgas feeding extensively on fishery wastes (hake) discarded by trawlers (Grémillet et al. 2008). This may explain the weaker association between feeding activity and fronts on the west coast (44\%) where gannets may follow fishing boats compared to the east coast (64\%) where birds seem not to feed on fishery wastes.

\section{Further directions}

Although the processes of concentration and enhancement of primary and secondary productions at fronts are rather well known, the mechanisms that drive the distribution and aggregation patterns of fish at fronts are still poorly understood (expect for very few studies e.g. Bertrand et al. 2008) and require particular attention, including observational and modeling studies. Focusing on top-predators (a mediumranging seabird species here), we showed that foraging behaviors, i.e., searching and feeding, are associated with external factors such as presence of mesoscale fronts. One may imagine that such behaviors are tightly connected to underlying physiological processes (involving energetic requirements, expenditure and investment) so that the physiological state of a bird would drive his behavioral response. The first step could be modeling the physiology of the bird using the dynamic energy budget theory (DEB, Kooijman 2010). The second step could be including this to a state-space model formulation in a Bayesian framework that would 
manage the behavior aspect (e.g. Jonsen et al. 2005, Patterson et al. 2008) in the way that the physiological states would induce changes in behavior.

\section{ACKNOWLEDGEMENTS}

The authors thank their respective affiliations listed above. Field studies on Cape gannets were funded by the Percy FitzPatrick Institute of African Ornithology, DST/NRF Center of Excellence at the University of Cape Town, South Africa, and by the CEFE-CNRS in Montpellier, France. Permission to conduct research was obtained from Cape Nature Conservation, West Coast National Parks, and South African National Parks and we thank them for their extensive logistics support. Philippe S. Sabarros thanks Marie Curie actions under FP6 (MEST-CT-2005-020932) through the CEES-MCO training site, and Norwegian Research Council (NFR-179569/V70). Eric Machu thanks the MICO project (NFR-ES427093). We are grateful to Tristan Rouyer for guidance on statistical analysis.

\section{REFERENCES}

Ainley DG, Dugger KD, Ford RG, Pierce SD, Reese DC, Brodeur RD, Tynan CT, Barth JA (2009) Association of predators and prey at frontal features in the California Current: competition, facilitation and co-occurrence. Marine Ecology Progress Series 389:271-294

Ainley DG, Spear LB, Tynan CT, Barth JA, Pierce SD, Glenn Ford R, Cowles TJ (2005) Physical and biological variables affecting seabird distributions during the upwelling season of the northern California Current. Deep-Sea Research II 52:123-143

Bakun A (2006) Fronts and eddies as key structures in the habitat of marine fish larvae: opportunity, adaptive response and competitive advantage. Scienta Marina 70S2:105-122

Bakun A (1996) Patterns in the ocean: ocean processes and marine population dynamics. University of California Sea Grant, San Diego, California, USA, in cooperation with Centro de Investigaciones Biologicas de Noroeste, La Paz, Baja 
California Sur, Mexico. 323 pp.

Barraquand F, Inchausti P, Bretagnolle V (2009) Cognitive abilities of a central place forager interact with prey spatial aggregation in their effect on intake rate. Animal Behaviour 78:505-214

Bertrand A, Gerlotto F, Bertrand S, Gutiérrez M, Alza L, Chipollini A, Díaz E, Espinoza P, Ledesma J, Quesquén R, Peraltilla S, Chavez F (2008) Schooling behaviour and environmental forcing in relation to anchoveta distribution: An analysis across multiple spatial scales. Progress in Oceanography 79:164-277

Bost CA, Cotté C, Bailleul F, Cherel Y, Charassin J-B, Guinet C, Ainley DG, Weimerskirch H (2009) The importance of oceanographic fronts to marine birds and mammals of the southern oceans. Journal of Marine Systems 78:363-376

Canyula JF, Cornillon (1992) Edge detection algorithm for SST images. Journal of Atmospheric and Oceanic Technology 9:67-80

Campagna C, Piola AR, Rosa Marin M, Lewis M, Fernández T (2006) Southern elephant seal trajectories, fronts and eddies in the Brazil/Malvinas Confluence. Deep-Sea Research I 53:1907-1924

Capet X, Colas F, Penven P, Marchesiello P, McWilliams J (2008) Eddies in eastern boundary subtropical upwelling systems. In: Eddy-resolving ocean modeling, Hecht M and Hasumi H eds. AGU Monograph, vol. 177, Washington, DC. p 350

Cotté C, Park YH, Guinet C, Bost CA (2007) Movements of foraging king penguins through marine mesoscale eddies. Proceedings of the Royal Society B 274:23852391

Crawford RJM, Sabarros PS, Fairweather T, Underhill LG, Wolfaardt AC (2008) Implications for seabirds of a long-term change in the distribution of sardine: a South African experience. African Journal of Marine Science 30(1):177-184 Davison AC, Hinkley DV (1997) Bootstrap methods and their application. Cambridge University Press

Durski SM, Allen JS (2005) Finite-amplitude evolution of instabilities associated with the coastal upwelling front. Journal of Physical Oceanography 35:1606-1628

Evans PGH (1982) Associations between seabirds and cetaceans: a review. Mammal Review 12(4):187-206

Fauchald P (2009) Spatial interaction between seabirds and prey: review and synthesis. Marine Ecology Progress Series 391:139-151

van Franeker J, van den Brink N, Bathmann UV, Pollard RT, de Baar HJW, Wolff WJ 
496

497

498

499

500

501

502

503

504

505

506

507

508

509

510

511

512

513

514

515

516

517

518

519

520

521

522

523

524

525

526

527

528

529

(2002) Responses of seabirds, in particular prions (Pachyptila sp.), to small-scale processes in the Antartic Polar Front. Deep-Sea Research II 49:3931-3950

Grémillet D, Pichegru L, Kuntz G, Woakes AG, Wilkinson S, Crawford RJM, Ryan PG (2008) A junk-food hypothesis for gannets feeding on fishery waste. Proceedings of the Royal Society B 275:1149-1156

Hockey P, Dean WRJ, Ryan PG (2005) Roberts Birds of Southern Africa. John Voelker Bird Book Fund

Hyrenbach KD, Veit RR, Weimerskirch H, Hunt GL (2006) Seabird associations with mesoscale eddies: the subtropical Indian Ocean. Marine Ecology Progress Series 324:271-279

Jonsen ID, Mills_Flemming J, Myers RA (2005) Robust state-space modeling of animal movement data. Ecology 86(11):2874-2880

Kooijman SALM (2010) Dynamic energy budget theory for metabolic organisation. Cambridge University Press

Le Corre M, Jaquemet S (2005) Assessment of seabird community of the Mozambique Channel and its potential use as indicator of tuna abundance. Estuarine, Coastal and Shelf Science 63:421-428

van der Lingen C, Hutchings L, Field JG (2006) Comparative trophodynamics of anchovy Engraulis encrasicolus and sardine Sardinops sagax in the southern Benguela: are species alternations between small pelagic fish trophodynamically mediated? African Journal of Marine Science 28(34):465-477

Longhurst AR (1998) Ecological geography of the sea. Academic Press

Manly BFJ (2006) Randomization, bootstrap and Monte Carlo methods in biology Chapman \& Hall/CRC

Nams VO (1996) The VFractal: a new estimator for fractal dimension of animal movement paths. Landscape Ecology 11(5):289-297

Nel DC, Lutjeharms JRE, Pakhomov EA, Ansorge IJ, Ryan PG, Klages NTW (2001) Exploitation of mesoscale oceanographic features by grey-headed albatross Thalassarche chrysostoma in the southern Indian Ocean. Marine Ecology Progress Series 217:15-26

Nevitt GA (2008) Sensory ecology on the high seas: the odor world of the procellariiform seabirds. Journal of Experimental Biology 211:1706-1713

Nevitt GA (2000) Olfactory foraging by Antartic procellariiform seabirds: Life at high Reynolds numbers. Biology Bulletin 198:245-253 
Nieto K (2009) Variabilidad oceánica de mesoescala en los ecosistemas de afloramiento de Chile y Canarias: una comparación a partir de datos satelitales. $\mathrm{PhD}$ thesis, University of Salamanca

Patterson TA, Thomas L, Wilcox C, Ovaskainen O, Matthiopoulos J (2008) Spacestate models of individual animal movement. Trends in Ecology and Evolution 23(2):87-94

Pauly D, Christensen V (1995) Primary production required to sustain global fisheries. Nature 374:255-257

Pedlosky J (1978) A nonlinear model of the onset of upwelling. Journal of Physical Oceanogrphy 8:178-187

Phillips RA, Xavier JC, Croxall JP (2003) Effects of satellite transmitters on albatrosses and petrels. The Auk 120(4):1082-1090

Pichegru L, Ryan PG, der Lingen CDV, Coetzee J, Ropert-Coudert Y, Gremilllet D (2007) Foraging behaviour and energetics of Cape gannets Morus capensis feeding on live prey and fishery discards in the Benguela upwelling system. Marine Ecology Progress Series 350:127-136

Ropert-Coudert Y, Grémillet D, Ryan P, Kato A, Naito Y, Le Maho Y (2004) Between air and water: the plunge dive of the Cape Gannet Morus capensis. Ibis 146:281-290

Sabarros PS, Grémillet D, Stenseth NC, Ryan PG, Machu E (in prep) A critical assessment of area-restricted search methods to identify feeding activity in seabird foraging movements.

Sabarros PS, Ménard F, Lévénez J-J, Tew-Kai E, Ternon J-F (2009) Mesoscale eddies influence distribution and aggregation patterns of micronekton in the Mozambique Channel. Marine Ecology Progress Series 395:101-107

Seki MP, Polovina JJ, Kobayashi DR, Bidigare RR, Mitchum GT (2002) An oceanographic characterization of swordfish (Xiphias gladius) longline fishing grounds in the springtime subtropical North Pacific. Fisheries Oceanography 11:5:251-266

Tew-Kai E, Rossi V, Sudre J, Weimerskirch H, Lopez C, Hernandez-Garcia E, Marsac F, Garcon V (2009) Top marine predators track Lagrangian coherent structures. Proceedings of the National Academy of Sciences USA 106(20):82458250

Trathan PN, Bishop C, Maclean G, Brown P, Fleming A, Collins MA (2008) Linear 
tracks and restricted temperature ranges characterise penguin foraging pathways. Marine Ecology Progress Series 370:285-294

Tremblay Y, Bertrand S, Henry RW, Kappes MA, Costa DP, Schaffer SA (2009) A review of analytical approaches to investigate seabird-environment interactions. Marine Ecology Progress Series 391:153-163

Tremblay Y, Roberts AJ, Costa DP (2007) Fractal landscape method: an alternative approach to measuring area-restricted searching behavior. Journal of Experimental Biology 210:935-945

Votier SC, Bearhop S, Witt MJ, Inger R, Thompson D, Newton J (2010) Individual responses of seabirds to commercial fisheries revealed using GPS tracking, stable isotopes and vessel monitoring systems. Journal of Applied Ecology 47:487-497

Weimerskirch H (2007) Are seabirds foraging for unpredictable resources? Deep-Sea Research II 54:211-223

Weimerskirch H, Le Corre M, Jaquemet S, Potier M, Marsac F (2004) Foraging strategy of a top predator in tropical waters: great frigatebirds in the Mozambique Channel. Marine Ecology Progress Series 275:297-308

Weimerskirch H, Le Corre M, Ropert-Coudert Y, Kato A, Marsac F (2005) The threedimensional flight of red-footed boobies: adaptations to foraging in a tropical environment?. Proceedings of Royal Society London B 272(1558):53-61

Wilson RP, Putz K, Peters G, Culik B, Scolaro JA, Charrassin J-B, Ropert-Coudert Y (1997) Long-term attachment of transmitting and recording devices to penguins and other seabirds. Wildlife Society Bulletin 25:101-106

Young JW, Bradford R, Lamb TD, Clementson LA, Kloser R, Galea H (2001) Yellowfin tuna (Thunnus albacares) aggregations along the shelf break off southeastern Australia: links between inshore and offshore processes. Marine and Freshwater Research 52:463-474

\section{FIGURE AND TABLE CAPTIONS}

Figure 1. Cape gannet tracks $(\mathrm{N}=20)$ recorded in October-November 2009 on the western and eastern coasts of South Africa.Figure 2. Cape gannet track (M1) recorded on 24-25/10/2009 (red line) on the west coast of South Africa superimposed onto the corresponding chlorophyll- $a$ concentrations map (1 km spatial resolution; $\mathrm{mg} \mathrm{m}^{-3}$, see 
598

599

600

601

602

603

604

605

606

607

608

609

610

611

612

613 Figure 6. Diving probability at front $(d=0)$ for tracks associated with fronts and those

614 with no association. Horizontal dotted line marks a probability of 0.5. In tracks

615

616

617 Table 1. Cape gannet tracks, foraging parameters and corresponding date of the

618 chlorophyll-a maps.

619

620 Table 2. Influence of fronts on ARS and diving activity. “*” indicates that the 95\%

621 bootstrapped confidence interval of $\beta$ does not overlap with 0 and that $\beta$ is therefore

622 significantly different from 0. FL computation failed for M7 and M9 (indicated by “-

623 ”. 


\section{FIGURES}

2 Fine-scale recognition and use of mesoscale fronts by foraging Cape gannets in the

3 Benguela upwelling region - Sabarros et al.

4

5

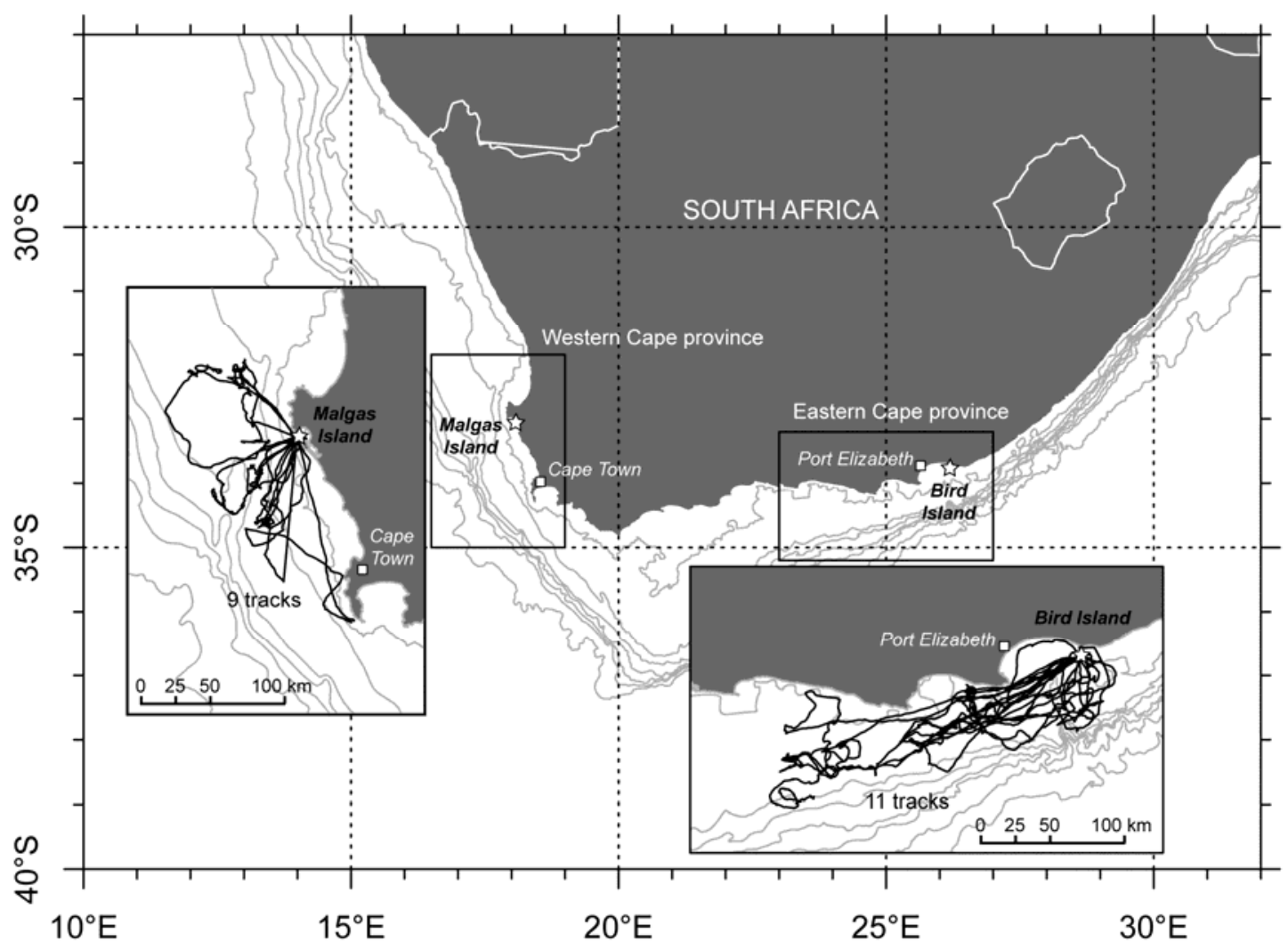

6 Figure 1. Cape gannet tracks $(N=20)$ recorded in October-November 2009 on the

$7 \quad$ western and eastern coasts of South Africa. 


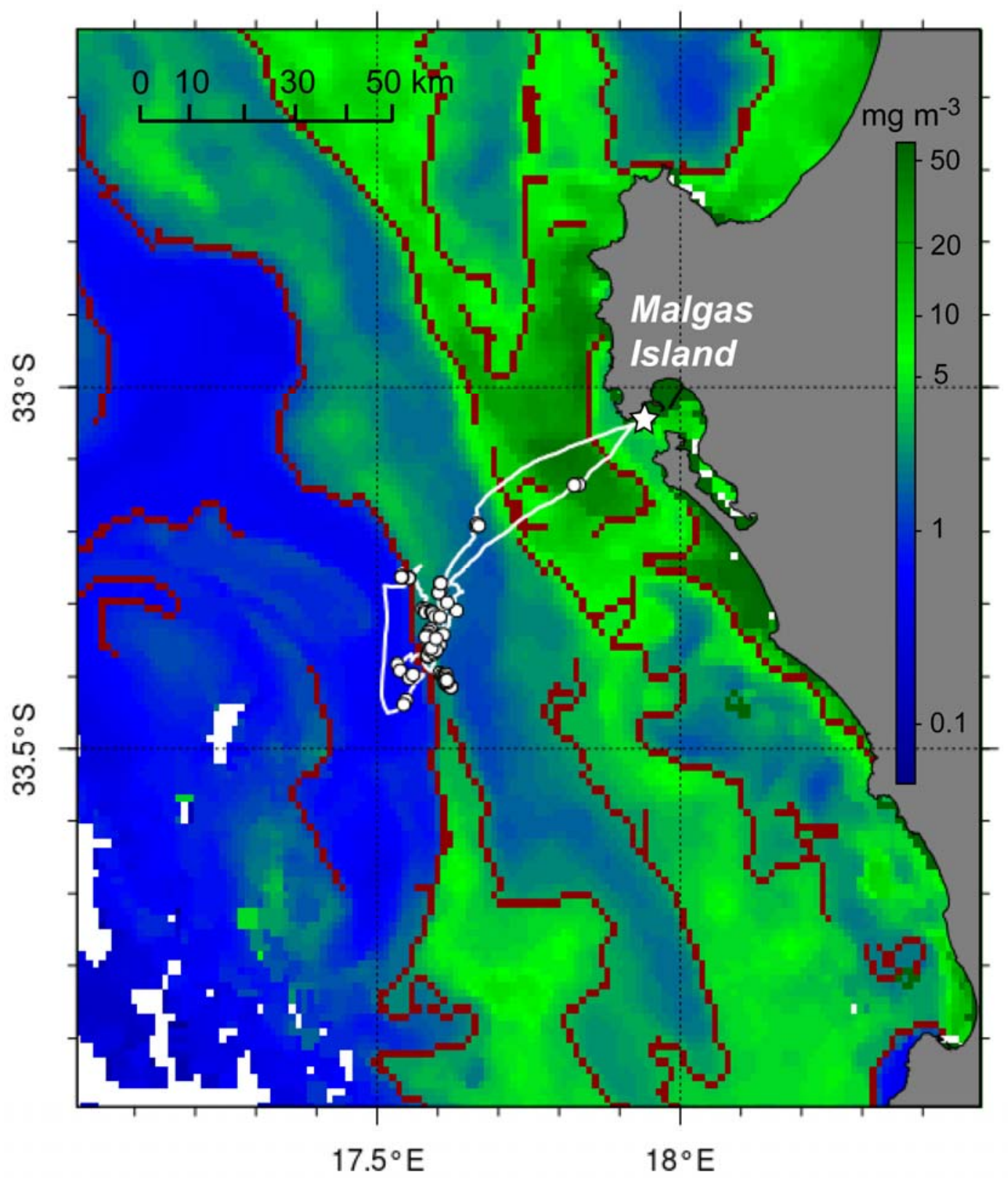

8 Figure 2. Cape gannet track (M1) recorded on 24-25/10/2009 (red line) on the west

9 coast of South Africa superimposed onto the corresponding chlorophyll $a$

10 concentrations map ( $1 \mathrm{~km}$ spatial resolution; $\mathrm{mg} \mathrm{m}^{-3}$, see color scale) with front

11 locations (dark blue lines). Dots indicates feeding spots. 
Track M2

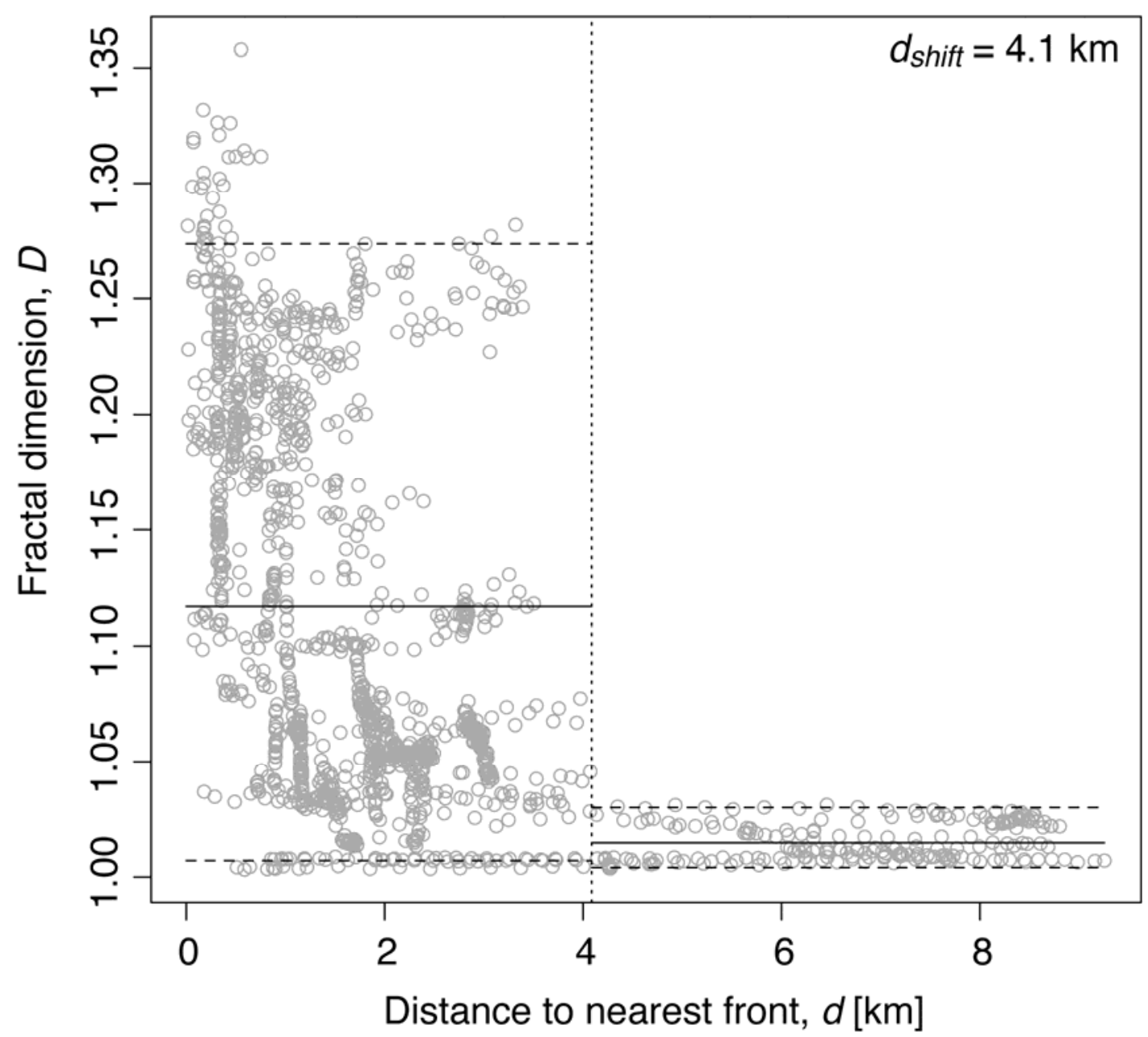

Figure 3. Behavioral shift in track M2 (24-25/10/09, Malgas Island). Fractal

14 dimension $D$ (= searching intensity) was computed along the track and is given as a

15 function of distance to front $d(\mathrm{~N}=90000$ observations). Vertical dotted line indicates

16 the shift at $d=d_{\text {shift. }}$ Horizontal solid lines are the means in the subsets $\leq d_{\text {shift }}$ and $>$

$17 d_{\text {shift }}$ and horizontal dashed lines represent the lower and upper quantiles (95\%). 


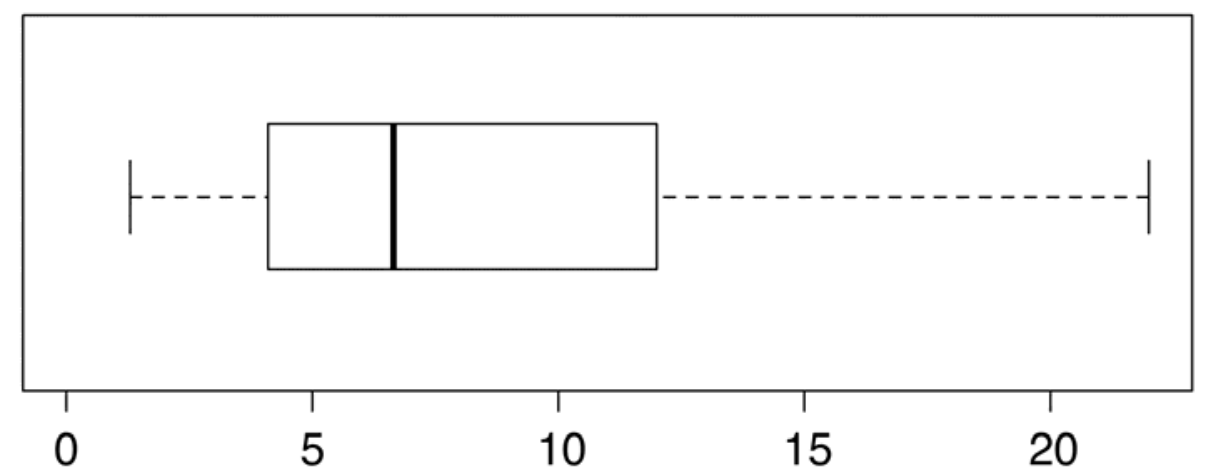

18

Distance to behavioural shift, $d_{\text {shift }}[\mathrm{km}]$

19 Figure 4. Behavioral shift distance to the nearest front $\left(d_{\text {shift }}\right) . \mathrm{N}=18$ tracks. Median is $20 \quad 6.7 \mathrm{~km}$.

21 
Track B1

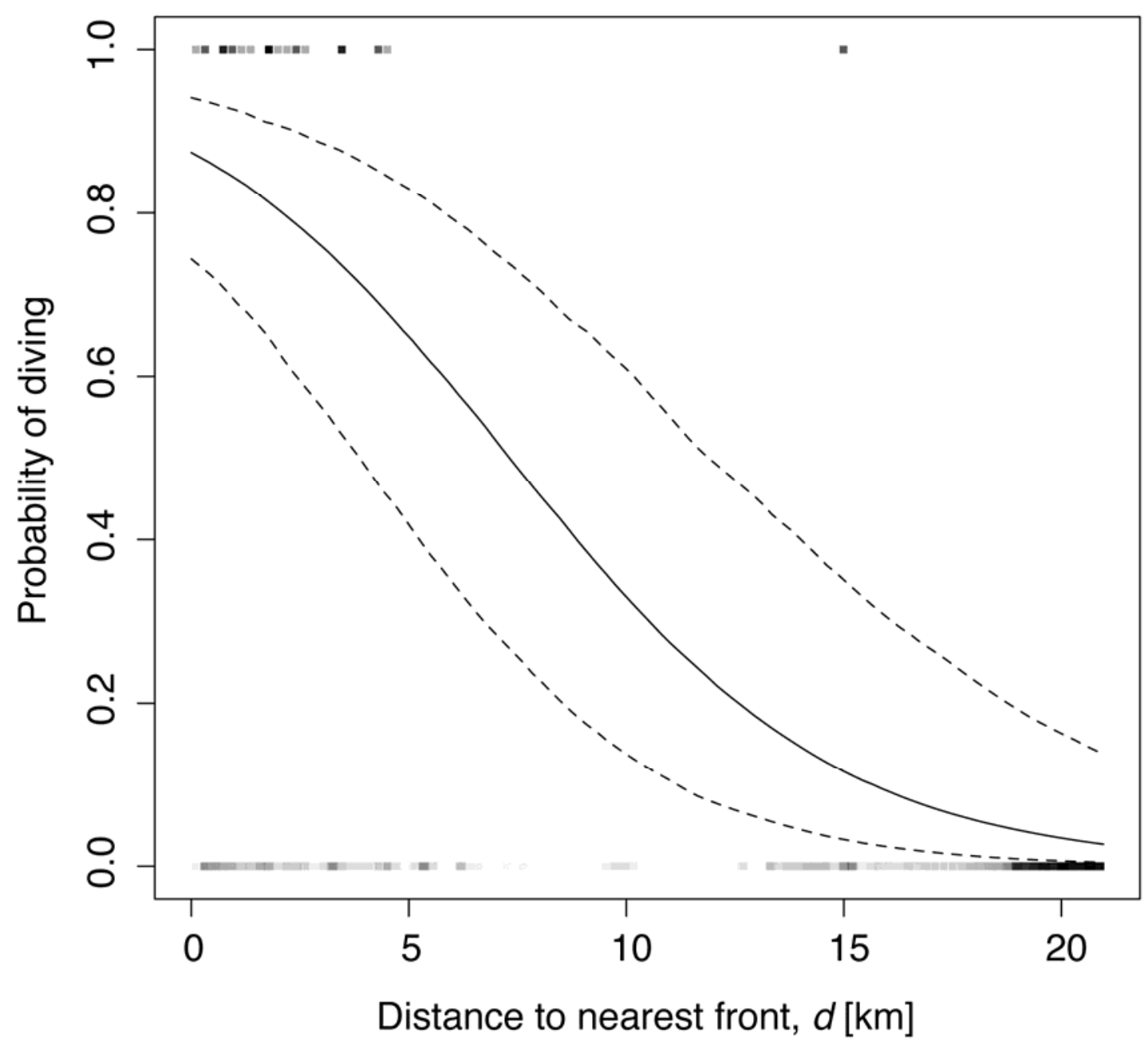

Figure 5. Probability of diving as a function of the distance to the nearest front in

24 track B1 (21-22/11/09, Bird Island). Solid line represents the mean effect and dashed

25 lines represent 95\% confidence interval. The density of observations of diving activity

26 is given for Dive $=1$ and Dive $=0$ along the $\mathrm{X}$-axis (grey shading). 


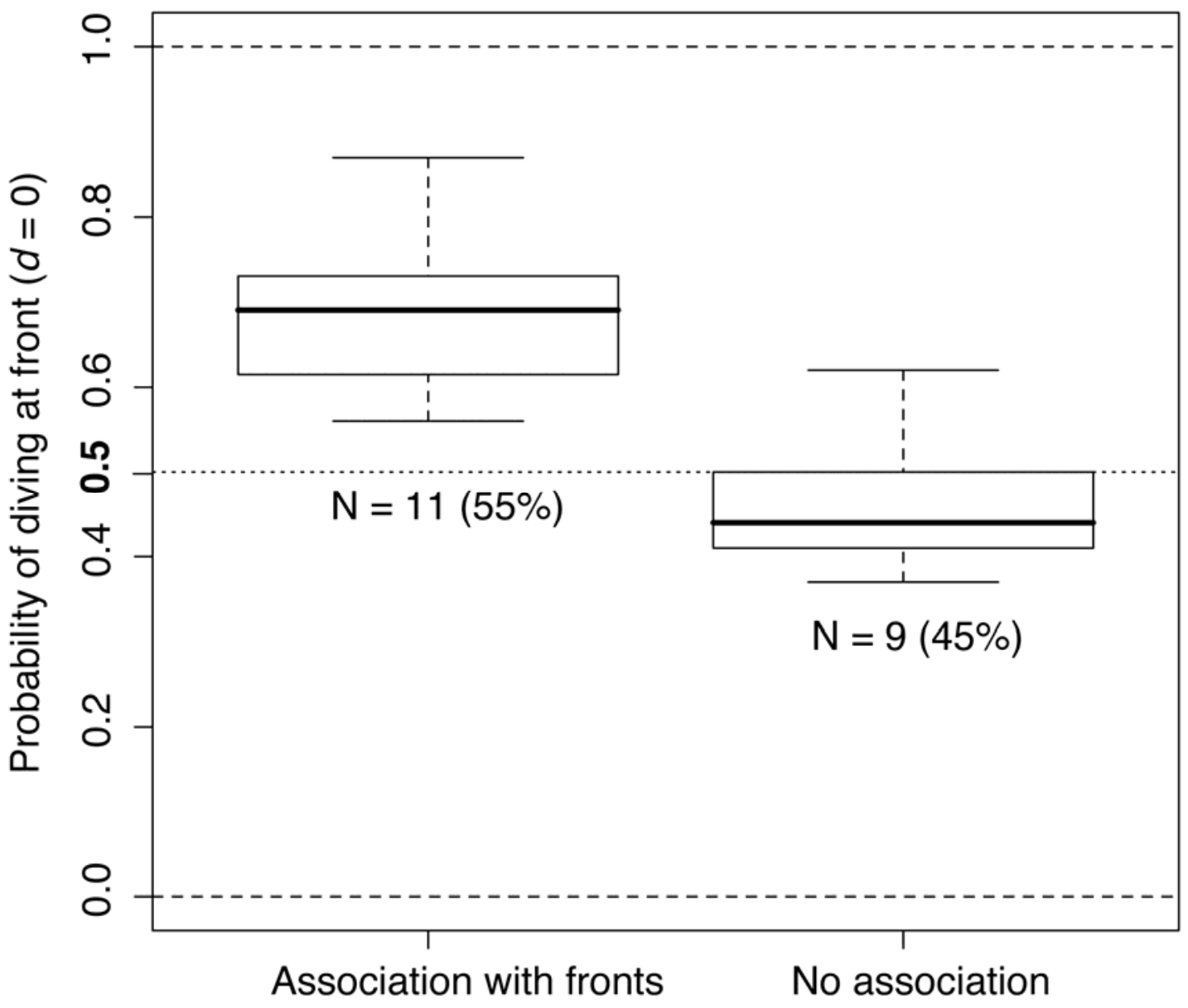

28 Figure 6. Diving probability at front $(d=0)$ for tracks associated with fronts and those

29 with no association. Horizontal dotted line marks a probability of 0.5. In tracks

30 associated with fronts the median is 0.7 , and 0.46 for those not associated with fronts. 


\section{TABLES}

32

33 Table 1. Cape gannet tracks, foraging parameters and corresponding date of the

34 chlorophyll-a maps.

\begin{tabular}{cccccccc}
\hline $\begin{array}{c}\text { Track } \\
\text { ID }\end{array}$ & Track name & Colony & Date & $\begin{array}{c}\text { Trip } \\
\text { duration } \\
\text { [h] }\end{array}$ & $\begin{array}{c}\text { Path } \\
\text { length } \\
\text { [km] }\end{array}$ & $\begin{array}{c}\text { N } \\
\text { dives }\end{array}$ & $\begin{array}{c}\text { chl-a } \\
\text { map(s) }\end{array}$ \\
\hline M1 & T0A_24OC & Malgas & $24-25 / 10 / 09$ & 25.2 & 313 & 68 & $25 / 10 / 09$ \\
M2 & T0B_24OC & Malgas & $24-25 / 10 / 09$ & 8.8 & 280 & 36 & $25 / 10 / 09$ \\
M3 & T0C_25OC & Malgas & $25-26 / 10 / 09$ & 9.54 & 278 & 69 & $25 / 10 / 09$ \\
M4 & T14_25OC & Malgas & $25-26 / 10 / 09$ & 15.84 & 297 & 59 & $25 / 10 / 09$ \\
M5 & T08_14NV & Malgas & $14-15 / 11 / 09$ & 21.6 & 363 & 26 & $15 / 11 / 09$ \\
M6 & T0E_20NV & Malgas & $20-21 / 11 / 09$ & 21.93 & 433 & 88 & $21 / 11 / 09$ \\
M7 & T0C_21NV & Malgas & $20-21 / 11 / 09$ & 21.8 & 357 & 48 & $21 / 11 / 09$ \\
M8 & T0C_22NV & Malgas & $22-23 / 11 / 09$ & 19.86 & 309 & 58 & $22-23 / 11 / 09$ \\
M9 & T0E_22NV & Malgas & $22-23 / 11 / 09$ & 22.85 & 532 & 61 & $23 / 11 / 09$ \\
B1 & BI-13-96_21-11-09 & Bird & $21-22 / 11 / 09$ & 15.31 & 228 & 27 & $22 / 11 / 09$ \\
B2 & BI-32-10_23-11-09 & Bird & $23-24 / 11 / 09$ & 21.22 & 395 & 77 & $23 / 11 / 09$ \\
B3 & BI-33-16_23-11-09 & Bird & $23-24 / 11 / 09$ & 19.67 & 403 & 58 & $23 / 11 / 09$ \\
B4 & BI-48-78_27-11-09 & Bird & $27-28 / 11 / 09$ & 10.09 & 305 & 28 & $28 / 11 / 09$ \\
B5 & BI-49-12_27-11-09 & Bird & $27-28 / 11 / 09$ & 21.21 & 438 & 54 & $28 / 11 / 09$ \\
B6 & BI-50-96_27-11-09 & Bird & $27-28 / 11 / 09$ & 22.8 & 517 & 28 & $28 / 11 / 09$ \\
B7 & BI-51-10_27-11-09 & Bird & $27-28 / 11 / 09$ & 26.38 & 607 & 151 & $28 / 11 / 09$ \\
B8 & BI-52-13_28-11-09 & Bird & $28-29 / 11 / 09$ & 24.85 & 737 & 49 & $28 / 11 / 09$ \\
B9 & BI-53-78_28-11-09 & Bird & $28-29 / 11 / 09$ & 18.74 & 481 & 22 & $28 / 11 / 09$ \\
B10 & BI-54-11_28-11-09 & Bird & $28-29 / 11 / 09$ & 28.12 & 923 & 105 & $28 / 11 / 09$ \\
B11 & BI-56-14_28-11-09 & Bird & $28-29 / 11 / 09$ & 33.01 & 703 & 93 & $28 / 11 / 09$ \\
\hline
\end{tabular}


35 Table 2. Influence of fronts on ARS and diving activity. “*” indicates that the 95\% bootstrapped confidence interval of $\beta$ does not overlap with 0 36 and that $\beta$ is therefore significantly different of 0 . FL computation failed for M7 and M9 (indicated by “-”).

\begin{tabular}{|c|c|c|c|c|c|c|c|c|c|c|c|}
\hline \multirow[b]{2}{*}{$\begin{array}{c}\text { Track } \\
\text { ID }\end{array}$} & \multicolumn{7}{|c|}{ ARS activity } & \multicolumn{4}{|c|}{ Diving activity } \\
\hline & $\begin{array}{l}d_{\text {shift }} \\
{[\mathbf{k m}]}\end{array}$ & $\begin{array}{c}\text { mean } D \mid d \\
\leq d_{\text {shift }}\end{array}$ & $\begin{array}{c}\text { mean } D \mid d \\
>d_{\text {shift }}\end{array}$ & $\Delta D$ & $p$ T-test & $p$ F-test & $\begin{array}{l}\text { Linked } \\
\text { to fronts }\end{array}$ & $\boldsymbol{\beta}$ & IC $95 \%$ & $\begin{array}{c}\operatorname{Pr}(\text { Dive }=1 \\
\mid d=0)\end{array}$ & $\begin{array}{l}\text { Linked } \\
\text { to fronts }\end{array}$ \\
\hline M1 & 3.1 & 1.101 & 1.029 & -0.072 & $<0.001$ & $<0.001$ & Yes & -0.35 & {$[-0.53,-0.19]^{*}$} & 0.76 & Yes \\
\hline M2 & 4.1 & 1.117 & 1.015 & -0.102 & $<0.001$ & $<0.001$ & Yes & -0.17 & {$[-0.33,0.02]$} & 0.59 & No \\
\hline M3 & 4.7 & 1.076 & 1.012 & -0.064 & $<0.001$ & $<0.001$ & Yes & -0.01 & {$[-0.12,0.09]$} & 0.50 & No \\
\hline M4 & 3.3 & 1.048 & 1.020 & -0.028 & $<0.001$ & $<0.001$ & Yes & 0.12 & {$[-0.01,0.28]$} & 0.37 & No \\
\hline M5 & 6.9 & 1.034 & 1.008 & -0.026 & $<0.001$ & $<0.001$ & Yes & 0.10 & {$[-0.18,0.46]$} & 0.42 & No \\
\hline M6 & 8.3 & 1.033 & 1.011 & -0.022 & $<0.001$ & $<0.001$ & Yes & -0.05 & {$[-0.09,-0.01] *$} & 0.56 & Yes \\
\hline M7 & - & - & - & - & - & - & - & -0.11 & {$[-0.27,0.02]$} & 0.62 & No \\
\hline M8 & 4.9 & 1.071 & 1.018 & -0.053 & $<0.001$ & $<0.001$ & Yes & -0.24 & {$[-0.37,-0.11]^{*}$} & 0.72 & Yes \\
\hline M9 & - & - & - & - & - & - & - & -0.19 & {$[-0.28,-0.12] *$} & 0.64 & Yes \\
\hline B1 & 2.1 & 1.048 & 1.008 & -0.040 & $<0.001$ & $<0.001$ & Yes & -0.26 & {$[-0.34,-0.20]^{*}$} & 0.87 & Yes \\
\hline B2 & 8.3 & 1.049 & 1.005 & -0.044 & $<0.001$ & $<0.001$ & Yes & -0.08 & {$[-0.14,-0.01] *$} & 0.56 & Yes \\
\hline B3 & 12 & 1.020 & 1.004 & -0.015 & $<0.001$ & $<0.001$ & Yes & -0.23 & {$[-0.35,-0.12]^{*}$} & 0.65 & Yes \\
\hline B4 & 6.4 & 1.039 & 1.010 & -0.029 & $<0.001$ & $<0.001$ & Yes & -0.10 & {$[-0.16,0.04]^{*}$} & 0.68 & Yes \\
\hline B5 & 19 & 1.012 & 1.005 & -0.007 & $<0.001$ & $<0.001$ & Yes & -0.11 & {$[-0.19,-0.04] *$} & 0.70 & Yes \\
\hline B6 & 22 & 1.016 & 1.005 & -0.011 & $<0.001$ & $<0.001$ & Yes & 0.04 & {$[-0.04,0.14]$} & 0.40 & No \\
\hline B7 & 9.2 & 1.025 & 1.005 & -0.020 & $<0.001$ & $<0.001$ & Yes & 0.09 & {$[-0.01,0.23]$} & 0.41 & No \\
\hline B8 & 1.3 & 1.069 & 1.014 & -0.055 & $<0.001$ & $<0.001$ & Yes & -0.38 & {$[-0.54,-0.24]^{*}$} & 0.74 & Yes \\
\hline B9 & 17 & 1.010 & 1.006 & -0.004 & $<0.05$ & $<0.05$ & Yes & 0.03 & {$[-0.06,0.12]$} & 0.44 & No \\
\hline B10 & 4.7 & 1.053 & 1.011 & -0.042 & $<0.001$ & $<0.001$ & Yes & -0.09 & {$[-0.13,-0.05]^{*}$} & 0.59 & Yes \\
\hline B11 & 15 & 1.021 & 1.001 & -0.020 & $<0.001$ & $<0.001$ & Yes & 0.02 & {$[-0.05,0.11]$} & 0.48 & No \\
\hline
\end{tabular}


- 9 - 
1 SUPPLEMENTARY MATERIAL

2 Fine-scale recognition and use of mesoscale fronts by foraging Cape gannets in the

3 Benguela upwelling region - Sabarros et al.

4

5 Section 1. Dive profile and identification

6

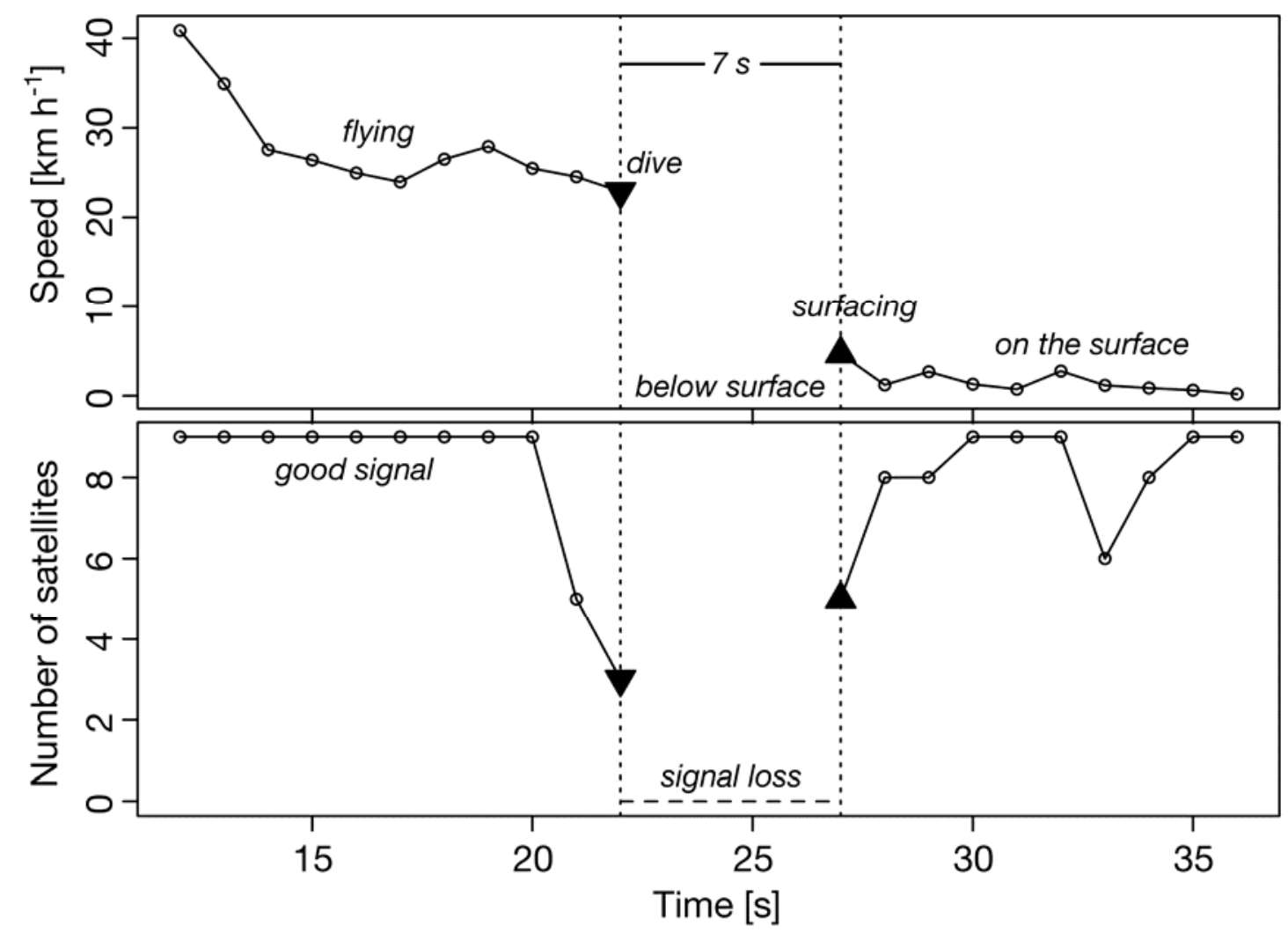

7

8 Figure S1. Plunge dive of a Cape gannet. (a) Speed and (b) number of satellite signals

9 received are shown to illustrate the signal interruption when the bird dives. The

10 example is taken from track BI-8-78_20-11-09 (14 ${ }^{\text {th }}$ dive $)$. 

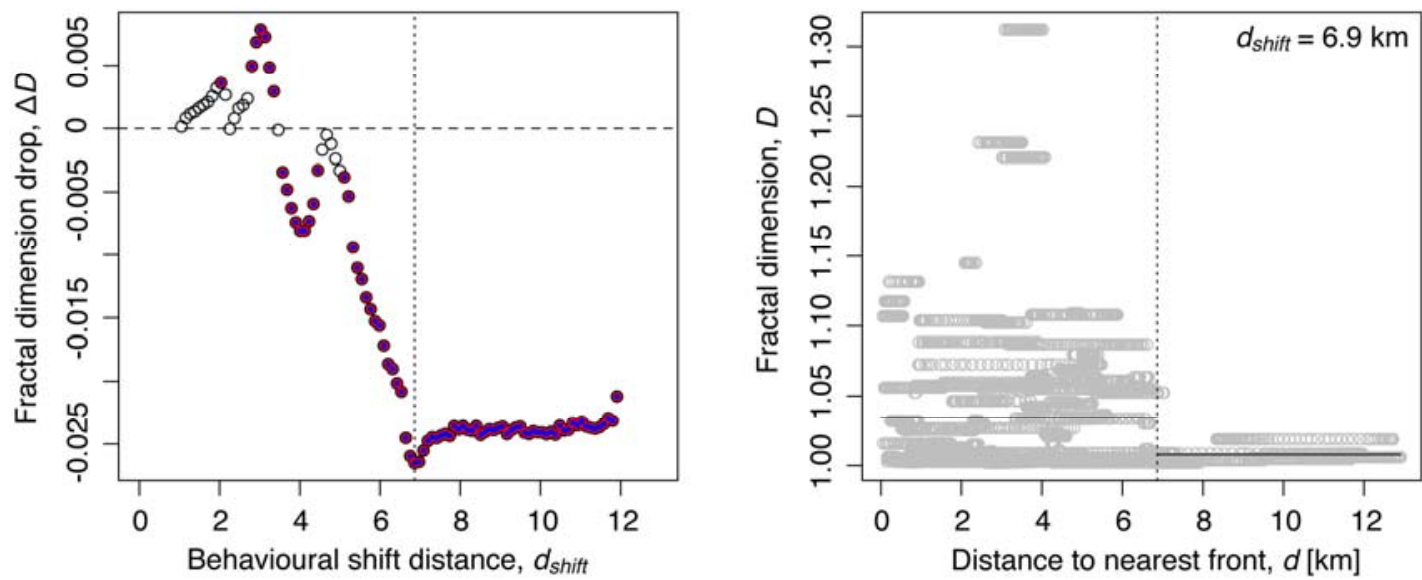

14 Figure S2. Behavior shift identification method. (a) Drop in fractal dimension $D$

15 between the subset $\leq d_{\text {shift }}$ and $>d_{\text {shift }}$ as a function of the distance threshold ( $\left.d_{\text {shift }}\right)$.

16 The blue filling and red circling of the dots indicate that, respectively, the $t$-test

17 (difference in mean) and the F-test (variance difference) comparing the two subsets

18 delimited by $d_{\text {shift }}$ are significant. (b) Fractal dimension $D$ as a function of $d$ showing

19 the behavior shift for the selected $d_{\text {shift }}$. 
Section 3. ARS activity vs. fronts
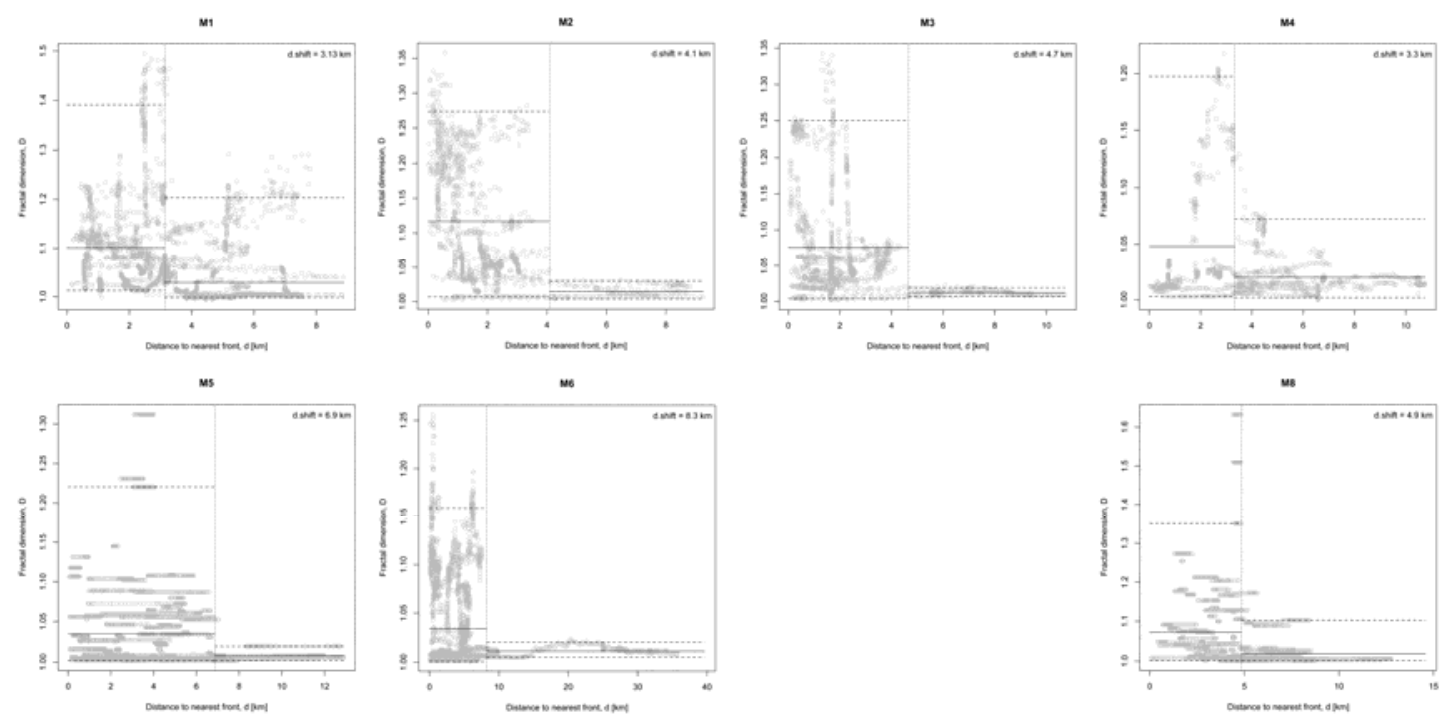

us

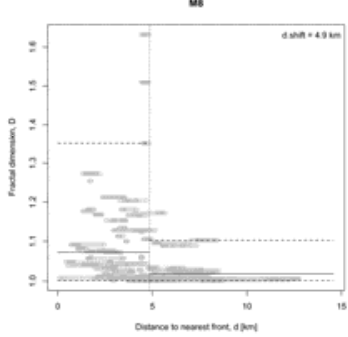

вง
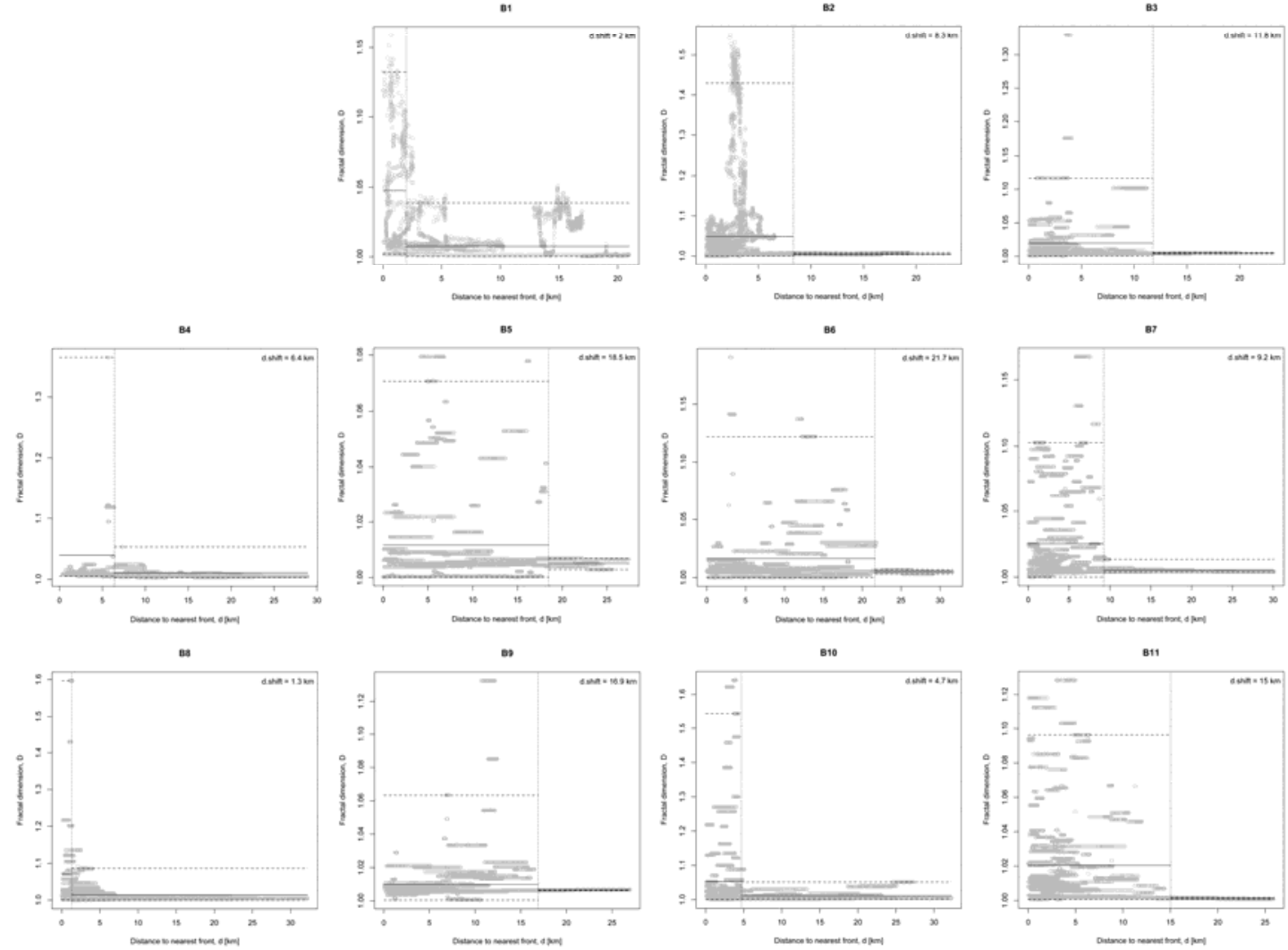

Figure S3. (a-t) Behavioral shift depending on the distance to fronts in all tracks investigated. Fractal dimension $D$ computed along the track is given as a function of the distance to the fronts $d$. The shift $d_{\text {shift }}$ is indicated by the vertical dotted line. The mean and 95\% confidence interval are represented by the solid and dashed lines (respectively) for the subset $\leq d_{\text {shift }}$ and $>d_{\text {shift }}$. 
Section 4. Diving activity vs. fronts
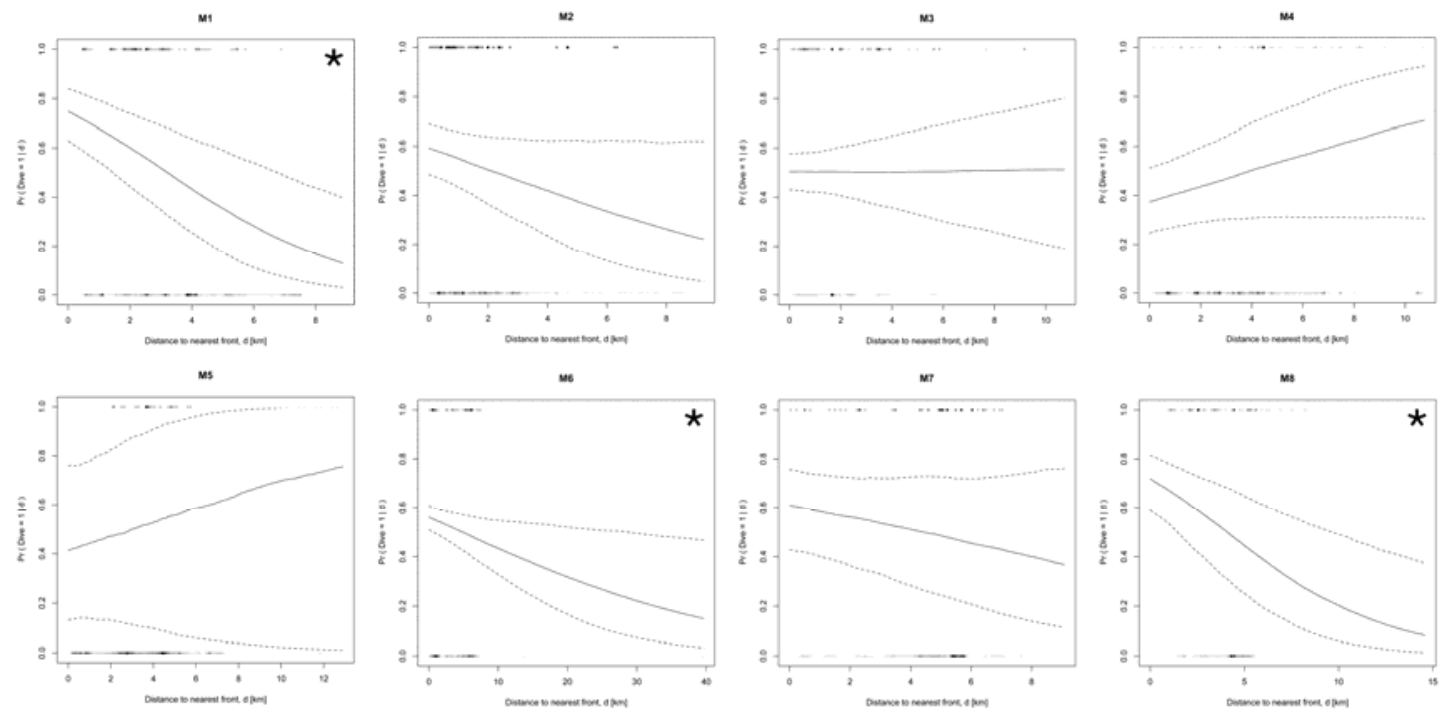

s1
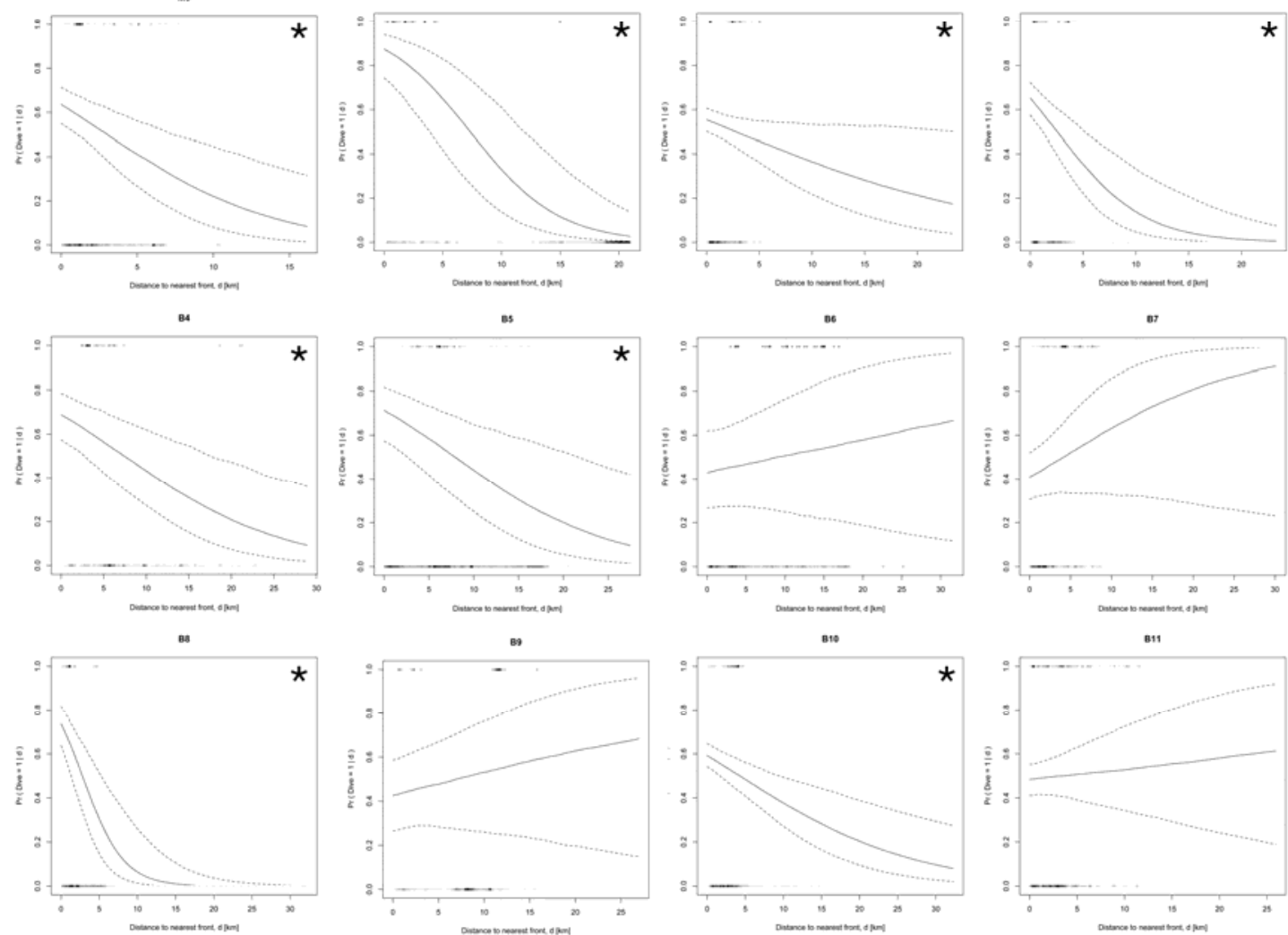

Figure S4. (a-t) Probability of diving as a function of distance to fronts in the 20 tracks investigated. The range of distances varies. Solid lines represent the mean

31 effect and dashed lines represent 95\% confidence. The density of observations of diving activity is given at $\operatorname{Pr}($ Dive $=1)$ and $\operatorname{Pr}($ Dive $=0)$ (grey shading). “*” indicates that the effect of $d$ is significant. 